\title{
UM ADVERGAME PARA BROWSER COMO CATALISADOR DA COMUNICAÇÃO: TIPOS DE COMUNICAÇÃO EM JOGOS DE VÍDEO
}

\author{
Heinrich Söbke \& Thomas Bröker
}

\begin{abstract}
Resumo
Os jogos de vídeo são media interativos abrangentes. Os jogos online incentivam a comunicação e alargam consideravelmente a gama de tipos de comunicação. Neste artigo, analisamos tipos de comunicação dominantes nos jogos de vídeo, utilizando o advergame para browser Fliplife. Este jogo proporciona uma estrutura clara, bem delimitada, um interface de utilizador pouco pretensioso e as características de jogo online de múltiplos jogadores. Assim, - Fliplife proporciona um excelente enquadramento para demonstrar a vasta gama de comunicação iniciada num jogo de vídeo. Entre os tipos de comunicação contemplados, encontram-se comunicações verbais e não verbais utilizando gráficos e ações/não ações. A comunicação encontrada serve, normalmente, para controlo e coordenação do jogo; porém, existem também discussões em privado e piadas sociais para além da demonstração do estatuto do jogador e da identificação da comunidade. Na presente investigação, partimos da definição básica de comunicação como transmitindo informações de um emissor para um destinatário. Categorizamos os tipos de comunicação encontrados segundo um modelo abstrato de comunicação decorrente de definições comuns. A compilação da numeração dos elementos da comunicação e das possíveis manifestações representa uma proposta de categorização da comunicação em jogos de vídeo, em geral. Apesar de ser necessária ainda uma validação mais exaustiva, esta enumeração mostra que os jogos de vídeo proporcionam enquadramentos que acomodam e iniciam uma diversidade de formas de comunicação. Uma diferença significativa, quando comparados com outros media, é que os jogos de vídeo e a sua noção de interatividade permitem aos jogadores comunicar através da ação e trocar os papéis de emissor e recetor.
\end{abstract}

\section{Palavras-chave}

Comunicação em jogos de vídeo; comunicação não verbal; comunicação através de ações/não ações; catalisador de comunicação; modelo de comunicação

\section{INTRODUÇÃO}

No contexto de bem-sucedidos e complexos jogos online de múltiplos jogadores, têm-se desenvolvido comunidades de jogadores ricas. A cultura de jogo daí resultante baseia-se na comunicação ativa dos participantes (Gee, 2008; Steinkuehler, 2006). Embora o sucesso comercial destes jogos assente nesta comunidade, sabe-se muito pouco acerca do enquadramento comunicacional dos jogos que incentiva estas comunidades.

Neste artigo, ilustramos a comunicação em jogos de vídeo utilizando o caso do Fliplife. Analisamos as características que promovem a comunicação do Fliplife, apresentando exemplos ilustrativos da mecânica de jogo relacionada com a comunicação. Estes resultados são mapeados num modelo de comunicação, tendo como resultado, para terminar, uma taxonomia de tipos de comunicação em jogos online de múltiplos jogadores (MOG). 


\section{Jogos DE VÍDEO COMO CATALISADORES DE COMUNICAÇÃO}

Os jogos de vídeo promovem novas formas de comunicação, faltando-lhes, por seu turno, tipos de comunicação enraizados. A comunicação face a face entre jogadores na vida real não é possível durante os jogos. Os gestos ou as expressões faciais não podem ser transferidos facilmente, mesmo que os jogadores partilhem a mesma sala. À medida que eles têm de observar o verdadeiro jogo, não podem olhar constantemente uns para os outros.

Como no caso dos MOG, os jogos de vídeo desenvolvem novos espaços virtuais como Terceiros Lugares (Steinkuehler \& Williams, 2006), que estão estreitamente ligados aos tipos de comunicação versáteis. Estabelecendo a ligação entre diferentes jogadores através de interesses e objetivos semelhantes, os jogos mostram como separar os jogadores da verdadeira experiência do jogo. Os jogadores estabelecem a ligação ao jogo pela sua "cultura", como Salen e Zimmerman (2003) descrevem no contexto de incorporação de um jogo, ou são envolvidos pelo "Jogo", como define Gee (2008). Trata-se de um processo que depende da comunicação, das experiências partilhadas, dos objetivos e dos ideais dos jogadores. Sem comunicação acerca das realizações, das estratégias, dos interesses, etc., não é possível desenvolver esta cultura.

Compreender a comunicação nos jogos proporciona uma oportunidade de a implementar propositadamente durante o processo de desenho do jogo, no sentido de melhorar a experiência de jogo, a fidelidade do cliente, os objetivos de marketing ou as experiências de aprendizagem. Apesar destas oportunidades, falta uma compreensão estruturada e abrangente da comunicação nos jogos de vídeo.

Os MOG de sucesso baseiam-se numa mecânica de jogo madura e complexa. Esta mecânica de jogo e a comunicação e cultura de jogo daí resultantes desenvolvem e mantêm uma comunidade de jogadores ativa. Os jogos nas redes sociais (SNG, Social Network Games), enquanto outra forma de MOG, encontram-se, normalmente, integrados nas comunidades existentes, mas falta-lhes a mecânica de jogo colaborativa para incentivar a verdadeira comunicação, para além de considerar os colegas jogadores como meros recursos (Söbke, 2014; Yee, 2014). Embora seja possível, a comunicação entre jogadores, encontra-se, normalmente, limitada a mensagens de estado, em vez de uma comunicação ativa e propositada.

O Fliplife é um SNG desenhado com um enfoque no jogo colaborativo. Esta é uma abordagem diferente daquela que é seguida por outros SNG, direcionados meramente para a recolha e decoração enquanto aspetos motivacionais. Devido ao seu revestimento purista e à ausência dessa mecânica de jogo típica, o Fliplife rejeita esse apelo. Pelo contrário, a sua mecânica de jogo simples incentiva a colaboração e a comunicação entre jogadores. A comunicação origina, quer a necessidade de colaboração orientada para o êxito, quer o interesse dos jogadores nos seus colegas jogadores ou na própria comunicação.

Na nossa perspetiva, estes aspetos identificam o Fliplife como um objeto de estudo adequado sobre a comunicação nos jogos de vídeo. Brüß et al. (2014) descobriram que o Fliplife pode ser considerado uma manifestação virtual de um Terceiro Lugar (Oldenburg, 
1999; Söbke \& Londong, 2015). Os jogos de vídeo como Terceiros Lugares virtuais foram abordados anteriormente (Steinkuehler \& Williams, 2006). No entanto, a existência deste fenómeno, sobretudo nos SNG, que são muito mais simples de manobrar do que os jogos de vídeo "tradicionais", não foi, até ao momento, abordada. Em certa medida, um SNG como Terceiro Lugar não é uma característica surpreendente, uma vez que os media propensos para a comunicação também são considerados como sendo capazes de possibilitar Terceiros Lugares (Soukup, 2006). O que conduz à questão sobre de que modos um jogo simplista como o Fliplife incentiva oportunidades de comunicação.

Por conseguinte, analisamos, entre maio de 2011 e setembro de 2014 , estas características do Fliplife, que promovem a comunicação, com base nas nossas experiências de jogo do Fliplife, ampliadas, se necessário, pelos resultados dos três inquéritos online que coordenámos (Brüß et al., 2014; Müller et al., 2012; Müller, 2012). Relacionamos exemplos representativos de comunicação no jogo com a mecânica do jogo correspondente. No nosso trabalho, diferenciamos sobretudo os tipos de comunicação que decorrem diretamente no jogo. Diversos media externos ao jogo, que podem ser utilizados como forma de comunicação sobre o jogo, são negligenciados: fóruns, blogs e redes sociais são apenas alguns deles.

Mapeamos estes resultados num modelo de comunicação em jogos online de múltiplos jogadores com base no modelo de comunicação de Lasswell (Lasswell, 1948), no modelo de Shannon-Weaver (Shannon, 1948)e nos resultados de "Social Interactions in Multiplayer Online Communities", de Siitonen (2007).

\section{O CASO DO FLIPLIFE}

O Fliplife é um SNG para browser que foi lançado em 2010 (e encerrado em 2014). Decorrente do seu programador suportado por capital de risco, foi anunciado como "uma plataforma de jogos de simulação de vida [...] internacional num cenário de vida real" ("Crunchbase: Fliplife," 2011). Esta descrição caracteriza muito bem o jogo: o jogador controla um avatar que passa por eventos da vida real. Fazem parte da vida do avatar, sobretudo, trabalho, atividades de lazer e amizade. No seu trabalho, o avatar participa em Projetos: o jogador tem de efetuar o registo num projeto e, depois de decorrido um determinado período de tempo, é oferecida uma recompensa que tem de ser recolhida num determinado período de tempo. Os eventos de lazer são constituídos por eventos desportivos, minijogos e festas. As relações com os outros jogadores têm de ser declaradas e sustentadas, uma vez que se baseiam em atividades comuns como participação em projetos e eventos de lazer. Um objetivo global consiste em recolher pontos de experiência $(X P)$ que determinam o nível do jogador. De acordo com o SNG comum, o Fliplife é (parcialmente) financiado por um modelo de preços Freemium, sendo outras fontes de rentabilidade as taxas das outras empresas anunciadas no Fliplife.

A estrutura do jogo é simples e espartana, comparativamente a outros jogos de vídeo em geral, e mesmo com outros SNG, em particular. Encontra-se reduzida a um conjunto mínimo de componentes e de mecânica do jogo. Uma vez que foi construído 
utilizando HTML5, quase não existem gráficos nem efeitos sonoros (SFX). No entanto, existem alguns fenómenos assinaláveis associados a este jogo. Os primeiros jogadores resolvem regularmente fenómenos complexos e transferem as recompensas para o futuro (Söbke, Bröker \& Kornadt, 2012). Os dois comportamentos não são normalmente atribuídos a jogadores de SNG (Bogost, 2010). Relacionado com estas observações do jogo emergente, foi divulgada uma utilização adicional do Fliplife: circulou a informação de que uma corporação alemã (Bayer AG) estava a fazer entrevistas de trabalho com base no seu jogo (Meyer, 2011). Uma abordagem deste género utiliza o Fliplife como plataforma de recrutamento para ser exequível, pelo menos teoricamente (Söbke, Hadlich, et al., 2012).

\section{O FLiplife À LUZ de UM ADVERGAME}

Originalmente, o Fliplife foi desenhado com o objetivo de proporcionar uma plataforma narrativa para empresas (Grabmeier, 2012). As empresas são um componente do trabalho de um avatar: cada jogador tem de escolher um empregador utilizando o seu avatar. Um empregador oferece um percurso profissional, com os passos comuns de carreira. No Fliplife, cada um destes passos da carreira exige aos jogadores que desenvolvam ações específicas, sendo estas constituídas, sobretudo, pela execução de projetos. Os projetos constituem uma forma de transferir mensagens sobre a empresa para o jogador, ou seja, um meio de narrativa. Entre as empresas da vida real que forneceram percursos profissionais encontram-se corporações como a Bayer, a Daimler e a Ernst \& Young.

Numa definição comum, um advergame consiste num jogo "no qual o próprio jogo é utilizado para transmitir uma mensagem do anunciante" (Rohrl, 2009; Wallace \& Robbins, 2006). Em consonância com esta definição, o Fliplife pode ser considerado um jogo deste tipo. Pode ser integrado num objetivo mais alargado como relações públicas ou marketing, que constituem formas específicas de comunicação de nível macro (Schmidt \& Zurstiege, 2000: 182). Normalmente, os advergames são concebidos para veicular a mensagem de uma determinada marca ou empresa (Terlutter \& Capella, 2013). O Fliplife, no entanto, proporciona um enquadramento que permite a veiculação de histórias de diversas empresas paralelamente.

(Müller, 2012) estudou aprofundadamente este enquadramento. A autora descreve de que modo a história - as mensagens a comunicar - está integrada no Fliplife como plataforma. Segundo os seus resultados, a história de uma empresa específica não se encontra disponível, a priori, no Fliplife através do design de jogos. Pelo contrário, tem de ser integrada no design do jogo predeterminado. Para o efeito, o enquadramento do Fliplife proporciona diversas opções de extensões. Estes elementos de extensão (gráficos e textuais) são utilizados para representar a empresa. Primeiro, é necessário definir uma carreira. A carreira é constituída por um número fixo de passos profissionais - hierarquias e posições - pelas quais o jogador terá de passar. As descrições textuais da empresa, a sua carreira e os percursos profissionais fornecem informações acerca da empresa. O avatar encontra-se decorado com as roupas de trabalho tradicionalmente 
utilizadas em cada tipo de cargo. Do mesmo modo, o conjunto de tipos de projeto revela informações: cada tipo de projeto descreve uma tarefa comum na empresa. Outros componentes extensíveis do jogo que incluem informações relacionadas com a empresa são as Ferramentas e os Materiais.

O conteúdo específico da empresa encontra-se integrado no Fliplife utilizando o conjunto de extensões descrito. Uma vez que este jogo foi criado como um advergame, coloca-se a questão da eficácia: os jogadores têm consciência dessas mensagens ou encontram-se apenas focados na mecânica do jogo? Müller (2012) realizou um inquérito online e encontrou indícios de que a abordagem está (pelo menos em parte) a funcionar: apenas $5 \%$ dos participantes nunca leem os nomes dos projetos e $24 \%$ nunca leem as descrições dos projetos $(n=127)$. Além disso, os nomes dos projetos poderiam ser identificados corretamente a uma taxa mais elevada, conforme ilustrado no exemplo em Tabela 1.

\begin{tabular}{|c|c|c|c|c|c|}
\hline Profissão & NOME DO PROJETO & SIM & $\begin{array}{c}\text { NÃO SABE/NÃO } \\
\text { RESPONDE }\end{array}$ & NÃo & Nota \\
\hline \multirow{3}{*}{$\begin{array}{l}\text { MÉDICO } \\
(\mathrm{N}=51)\end{array}$} & Retirar o apêndice & 45 & 3 & O & \\
\hline & Fazer limpeza aos dentes & 6 & 6 & 30 & Projeto não existe \\
\hline & Praticar caligrafia ilegível & 45 & 2 & 1 & \\
\hline
\end{tabular}

Além disso, para algumas empresas é necessário responder a perguntas como pré-requisito de progressão. Esta constitui a forma mais óbvia de transferência de conhecimento. Quando é colocada a questão "Desde quando é que a E-Plus é considerada empregador de topo?", então a resposta é 2005. Contudo, uma mensagem importante desta questão é "A E-Plus é um empregador de topo".

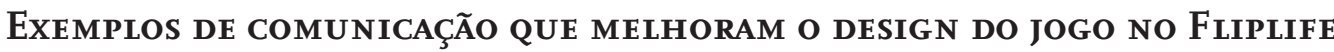

\section{PRojetos Como conflitos desen HADOS}

Um Projeto é uma metáfora elaborada que designa a colaboração entre jogadores. Existe um conjunto de diferentes tipos de projeto para cada percurso profissional. Um projeto é definido pelo número de locais de trabalho (entre 1 e 8 jogadores), pela sua duração (10 seg. a 72 horas) e pelo intervalo de tempo destinado a recolher os ganhos do projeto ( 3 horas a 24 horas). Participar num projeto exige apenas alguns cliques básicos por parte do jogador: quando se regista no projeto e quando recolhe a recompensa. Se todos os jogadores recolherem os seus ganhos atempadamente, todos os jogadores do projeto recebem um bónus adicional. Além disso, o projeto é contabilizado como estando concluído, o que é importante para ordenar as listas e os percursos profissionais. Este aspeto representa uma implicação importante: o êxito de um jogador depende da fiabilidade dos seus colegas. Registaram-se diversas estratégias destinadas a aumentar a taxa de sucesso dos projetos, todas elas incluindo a comunicação. 
Trabalhar em grupos (quase) fechados é uma dessas abordagens, que conduz a comunidades nas quais os jogadores se conhecem muito bem. Regra geral, essas comunidades comunicam durante longos períodos de tempo. Este fenómeno é sustentado pela componente do jogo Departamento, que constitui uma oportunidade de os jogadores colaborarem com vista a alcançarem um objetivo partilhado e a desenvolverem um branding próprio. Inclui um determinado número de membros (10 a 25), possui uma estrutura hierárquica e pode construir as designadas capacidades. As capacidades aumentam as possíveis dimensões e eficiência de um departamento. Observámos que a introdução de departamentos no jogo aumentou a comunicação entre os jogadores. Nas fases iniciais do jogo, havia apenas uma conversa transversal ao jogo, que não era comummente aceite pelos jogadores. Era parcialmente transbordante e confusa devido ao elevado volume de mensagens. Conclui-se, com base nesta experiência, que o design do jogo deveria permitir a formação de grupos mais pequenos, de modo a incentivar possibilidades de comunicação.

Uma observação adicional é que os jogadores lembram outros jogadores para recolherem o seu prémio: cada projeto possui o seu próprio chat de projeto. As mensagens novas deste chat são entregues num centro de mensagens, onde são claramente assinaladas, acompanhadas por um breve aviso sonoro. Se um jogador pretender lembrar outros jogadores para recolherem o seu prémio, faz um comentário curto no chat do projeto e todos os colegas recebem uma dica para recolherem o seu prémio. Deste modo, a ânsia de ter êxito leva à comunicação.

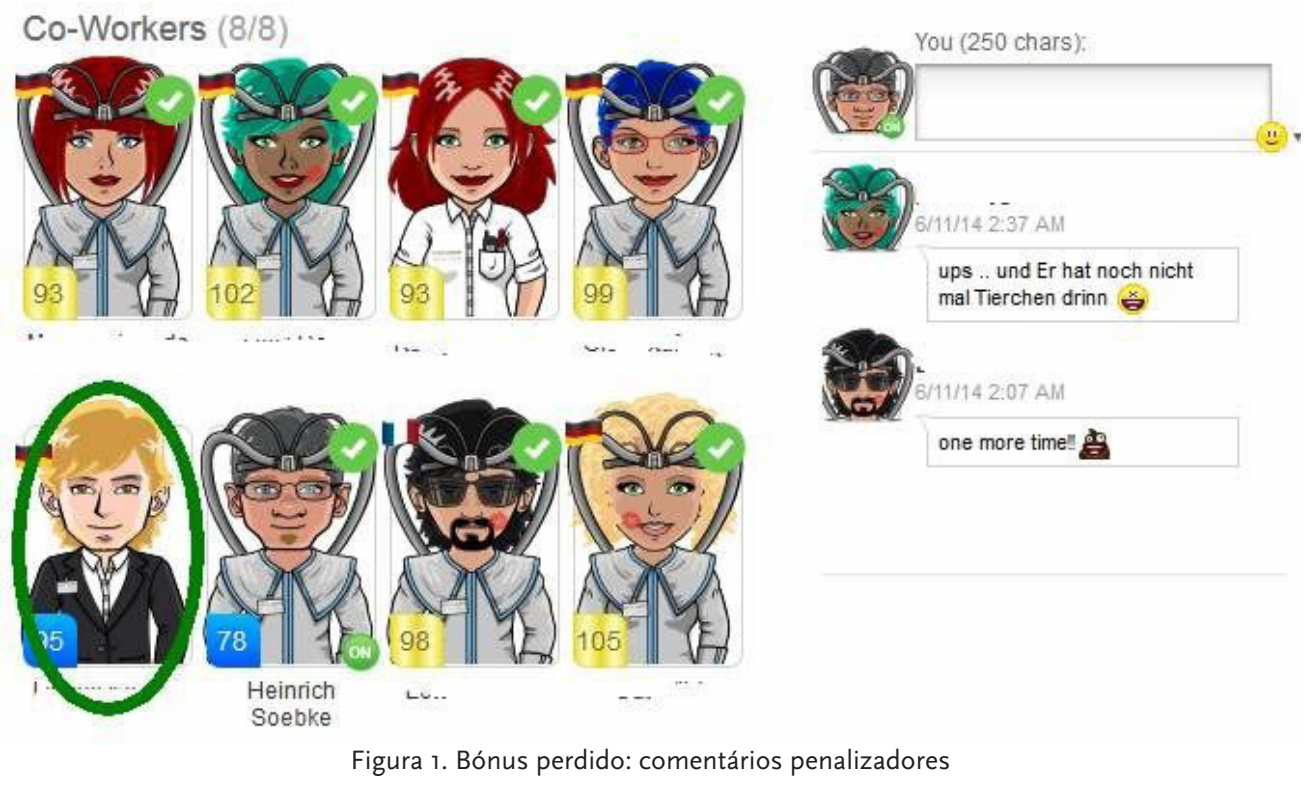

Existe uma escala para relembrar outros jogadores: quando um projeto falhar, alguns jogadores penalizam os membros da equipa incumpridores, enunciando a sua desilusão no chat do projeto (ver Figura 1). Esta acusação semipública coloca alguma pressão sobre os jogadores incumpridores, que podem procurar ser mais fiáveis no futuro. Este é outro exemplo de como o design do jogo suscita conflitos, que são obviados para o grupo através da comunicação. 
Uma alternativa a ter de lidar com estes conflitos é evitá-los; esta abordagem está, também, ligada à comunicação: um projeto é concretizado jogador a jogador. Quando a última vaga para jogadores num projeto estiver preenchida, o projeto começa. Os projetos não concretizados podem ser verificados; uma informação importante é a taxa de sucesso do jogador, isto é, a percentagem de projetos que o jogador concluiu com êxito, comparativamente a todos os projetos nos quais participou. Os jogadores com um desempenho fraco podem ser identificados deste modo. Para cada tipo de projeto, existe apenas um projeto de recursos humanos a decorrer. Se essa vaga num projeto ainda por iniciar for preenchida por um jogador com uma fraca taxa de sucesso, os outros jogadores podem ter relutância em participar no projeto, prevendo uma fraca probabilidade de êxito no projeto. É aqui que decorre a comunicação através de uma não-ação: o projeto não é, de todo, preenchido ou é preenchido muito lentamente. Em casos extremos, outros jogadores procuram incitar o jogador com fraco desempenho a abandonar o projeto, através de comentários no chat do projeto.

Uma outra fase da estratégia evasiva descrita consiste na gestão proativa desses projetos, o que acontece quando um jogador incentiva outros jogadores aparentemente (ou garantidamente) fiáveis a participar no projeto, uma vez mais através da comunicação textual. Mas também existem outras facetas relacionadas com o facto de assegurar ativamente a fiabilidade para com outros jogadores. Um avatar é assinalado quando o jogador se encontra online. Se um jogador, que tenha acedido a participar num projeto de curto prazo, não estiver online, tal pode ser interpretado por outros jogadores interessados em participar como sendo um mau augúrio. Estes potenciais jogadores preveem o fracasso do projeto e não participam no mesmo. Contudo, o jogador, que está online, pode ter utilizado a opção Recolher automaticamente. Esta opção tem de ser comprada utilizando a moeda física (Kelly, 2010) do jogo (designada Flips e disponível para aquisição utilizando dinheiro real) e dispensa o jogador da obrigação de recolher o prémio atempadamente. Por conseguinte, o bónus do projeto não está em risco por uma não-ação potencial do jogador offline. Infelizmente, a capacidade de utilização desta opção não se encontra visível para outros jogadores. Por esse motivo, os jogadores que optam pela Recolha automática indicam muitas vezes este facto através de um comentário no chat do projeto. Na gíria em alemão, o termo é "AA" ("Autoabholung").

Cada uma das estratégias de colaboração descritas está relacionada com um determinado tipo de comunicação. Consequentemente, um jogador tem de comunicar para aumentar o seu êxito no jogo. O componente do jogo Projeto é um exemplo de um conflito desenhado, que cria uma procura latente de comunicação.

\section{Projetos de bónUS COMO INCUBADORAS DE TROCA}

O bónus de um projeto pode ser aumentado através da utilização de impulsionadores. No Fliplife, designam-me Material e Ferramenta. Estes propulsores aumentam o bónus de forma linear, ou seja, quantos mais materiais forem utilizados, mais elevado será o bónus do projeto, e fazem parte do prémio de um projeto de sucesso. Por isso, 
cada um dos materiais representa um projeto concluído. Para a produção de um elevado número de materiais, existem "sessões de produção": normalmente, no final do dia, quando os jogadores desfrutam do seu tempo livre, reúnem-se nos seus departamentos no jogo e, em conjunto, concretizam breves projetos com múltiplos jogadores (isto é, de 5 min.) para produzir material. Nestas sessões, os jogadores têm de participar nos projetos e de recolher os prémios. Necessitam de se manter no teclado quase continuamente para participarem nos projetos de modo eficiente. Uma vez que estas ações preenchem apenas uma pequena parte do tempo disponível, resta ainda algum tempo para comunicação textual, o que pode ser observado como sendo um comportamento comum de uma parte significativa dos jogadores.

Os termos Material e Ferramenta estão estreitamente ligados ao termo Projeto bónus. Esta metáfora do sucesso do jogo a uma escala épica influencia o jogo de praticamente todos os jogadores de longa data. A mecânica do jogo, conforme proposta explicitamente pelo design do jogo, é simples, como demonstra o exemplo do Projeto na secção anterior. Contudo, ao longo do tempo, o hábito do Projeto bónus emerge como um objetivo definido pelo jogador. Este é um projeto que utiliza um elevado número de materiais. Consequentemente, o ganho de XP e de Moedas torna-se imenso comparativamente a um projeto normal. Só para exemplificar esta amplitude: participámos num projeto com um prémio 6000 vezes superior ao habitual, o que teve como resultado mais de 20000 Materiais e Ferramentas adequados (ver Figura 2). 20000 Materiais equivale a mais ou menos 20000 projetos finalizados. Este é um enorme esforço por parte dos jogadores e que é posto em causa: se apenas um participante não recolher o seu prémio atempadamente, o bónus será rejeitado. Um projeto destes necessita de participantes fiáveis. Conforme descrito na secção anterior, aumenta drasticamente o potencial de conflito.

Um efeito adicional é a ocorrência de troca de material. Conforme descrito anteriormente, um Material é um dos prémios de um projeto. Existem diferentes tipos de Materiais. Um Material é produzido independentemente da carreira do jogador, mas projetos específicos da carreira necessitam de materiais específicos. Ou seja, uma grande parte do material premiado não é diretamente utilizável para o jogador, que segue uma carreira dedicada. Uma forma de contornar esta situação é trocar material não utilizável. Outros jogadores necessitam deste tipo de material e podem, por sua vez, oferecer material que não podem utilizar. O processo de troca exige comunicação: consiste em identificar jogadores adequados, procurar o seu armazenamento e, finalmente, negociar com eles. No seu conjunto, a metáfora do Material constitui um componente adicional do design do jogo que leva os jogadores a despenderem um esforço enorme para trocarem esses itens. Este processo é acompanhado, uma vez mais, por comunicação: comunicação funcional, no caso de troca, e, sobretudo, comunicação voluntária, no caso de produção de material. Um resultado adicional é o surgimento da característica de jogo emergente de Projetos bónus. 


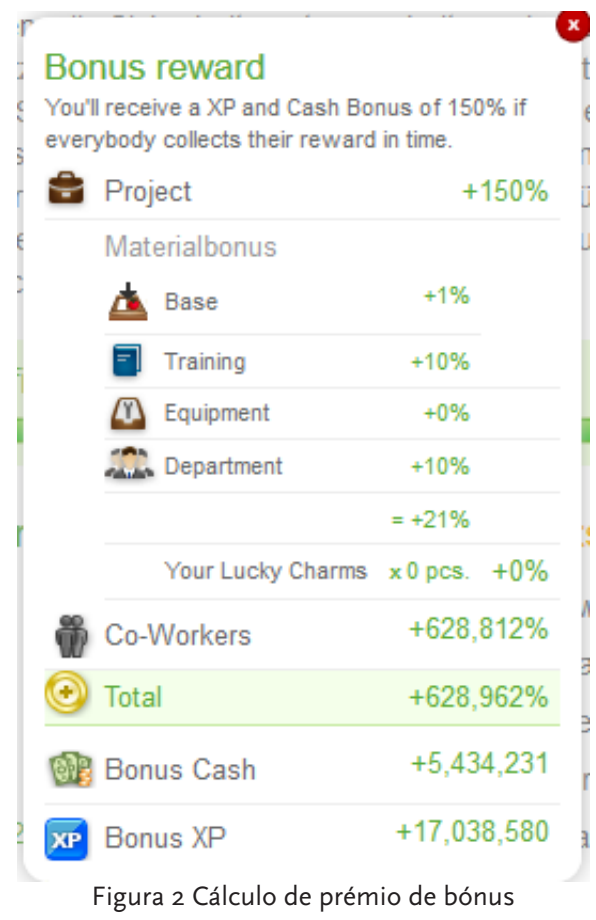

\section{A PROCURA DE ENERGIA: RECOLHA DE RECURSOS COMUNICATIVOS}

Participar num projeto requer recursos de Energia renovável. Durante sessões de produção, a energia esgota-se mais rapidamente do que é produzida. Por isso, os jogadores têm de produzir energia. Esta produção é realizada através de eventos nos tempos livres. As Festas constituem um meio popular de gerar energia. Como na vida real, um jogador tem de iniciar a festa e convidar outros jogadores. Cada jogador tem de aceitar o convite. O objetivo de uma festa é gerar um determinado lucro. Cada jogador pode convidar os outros participantes para uma bebida. Se forem compradas demasiadas bebidas simultaneamente, o ambiente torna-se exuberante e a festa é um fracasso. Por isso, os jogadores têm de utilizar uma estratégia colaborativa para comprar bebidas continuamente a um preço baixo, mas estável. É necessária comunicação: nas fases anteriores do jogo, os convidados para a festa estavam divididos em três grupos. Posteriormente, o anfitrião direcionou esses grupos para comprarem bebidas. Cada um dos grupos dispunha de um período de tempo para comprar bebidas. Mais recentemente, surgiu outro hábito: o anfitrião gastou todas as rodadas. Em suma, a mecânica do jogo de uma festa constitui um indutor de comunicação que utiliza diferentes media e hábitos.

\section{UM MOdelo mais ReAlista de AMIZADE}

A amizade é uma componente essencial nos SNG, funcionando, sobretudo, numa base mútua: um jogador tem de pedir amizade e outro jogador tem de confirmar a proposta. Esta é, também, a forma como funciona no Fliplife. Além disso, o Fliplife utiliza níveis de amizade. O nível depende do grau de ações comuns. As ações comuns consistem, por exemplo, em participar nos mesmos projetos e nas mesmas festas. O nível 
baixa sempre que não existir uma atividade comum nos últimos 30 dias. Dependendo do nível de amizade dos participantes num projeto, é concedido um bónus social. Trata-se de uma fonte adicional de XP, sobretudo no caso de produção de material (cf. Sec. Projetos de bónus como incubadoras de troca). Consequentemente, observámos que o modelo de Amizade implementado permite aos jogadores lutarem para criar a Amizade. Torna-se um objetivo do jogo e, por conseguinte, acelera a ligação social, as interações sociais e, finalmente, a comunicação.

Este modelo de Amizade constitui um componente de design que levou à formação de comunidades no Fliplife. A criação de uma comunidade estabelecida proporciona formas de comunicação adicionais: no início de 2012, o programador do jogo alterou algumas regras da mecânica do jogo no Fliplife. Muitos jogadores não concordaram com as alterações. Por isso, iniciaram uma campanha para deixar bem clara a sua discórdia relativamente a essas novas regras. Cada um dos jogadores podia participar na campanha pintando o cabelo de púrpura (Männl, 2012). Deste modo, o jogador individual comunica com os seus colegas jogadores e a comunidade de jogadores envia uma mensagem ao designer do jogo.

\section{JUNTANDO TEORIA E PRÁTICA: UMA PERSPETIVA FORMAL do FLIPLIFE}

\section{ativação da comunicaçÃo: o melo}

Qualquer processo de comunicação utiliza um meio. No Fliplife, prevalecem diversos media. O meio dominante é o texto. A comunicação textual é despoletada no jogo em diversos locais: está disponível uma ferramenta de chat para o próprio jogo, para cada projeto, para cada festa e para cada departamento. Um quadro de mensagens permite a comunicação assíncrona a nível do jogador e a nível do departamento. Adicionalmente, um jogador pode enviar mensagens pessoais a outro jogador. A comunicação textual é alargada através da utilização de ícones emotivos. Estes são oferecidos sobretudo para contributos de conversação e constituem uma forma de comunicação gráfica. Um subtipo dos gráficos do meio é o avatar do jogador. Trata-se de uma fotografia 2D. A sua personalização no Fliplife é sofisticada; o editor do avatar é estruturado de modo semelhante ao software de imagem identikit. Além disso, permite a seleção de fatos para diversas fases da vida. Outro componente da personalização é uma mensagem de texto: um slogan na página de perfil do jogador. Também o nome do jogador se tornou uma forma de meio: nas fases iniciais do jogo, era comum utilizar-se o nome da vida real, o que era promovido pela autorização do Facebook. Posteriormente, os nomes passaram a ser selecionados de forma criativa. Por conseguinte, constituem um tipo de meio (ver Figura 3). 


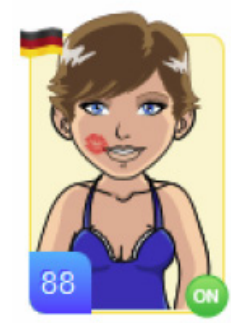

Emely Schubert

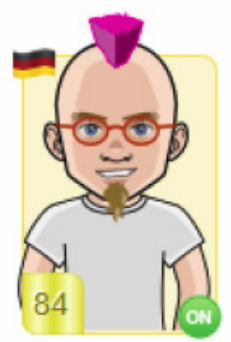

Squeezie Diner

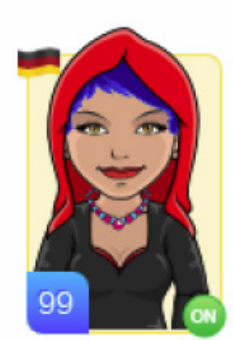

Club Stufor $Q$.

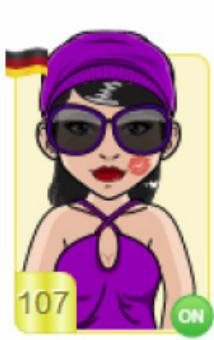

Sabine Biene-Stat

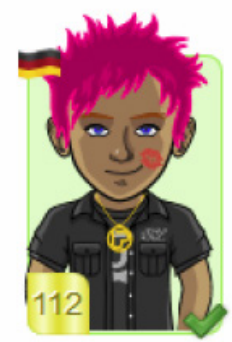

Marcel Koch-Marin

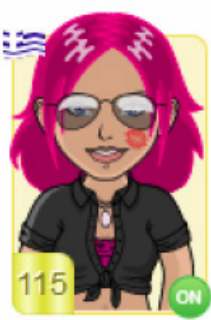

Alice Christ.

Figura 3. Convidados da festa com fatos adequados

O estatuto do jogador é um tipo de meio. $O$ estatuto é expresso através de texto ou gráficos. Os jogadores, que estão a pagar um estatuto "Premium", surgem ornamentados com uma cor de fundo a amarelo. O nível de um jogador é apresentado com um avatar (ver Figura 3).

As Ações podem ser consideradas um meio (não-verbal). A Amizade no Fliplife é um exemplo: a dimensão do bónus num projeto revela informações acerca do volume de atividades comuns no passado (cf. Sec. Um modelo mais realista de Amizade). De igual modo, as não-ações podem transferir informações do emissor para o recetor. Um exemplo consiste em evitar um projeto, juntamente com um jogador com uma fraca taxa de sucesso (cf. Sec. Projetos como conflitos desenhados). Um dos problemas das não-ações é que não podem ser claramente reconhecidas pelo recetor.

Um outro exemplo de ação como meio é a lista de pontuação dependente do tipo de projeto. Cada tipo de projeto apresenta uma lista dos três jogadores que utilizaram a maioria do material nestes projetos. Nos projetos mais curtos, a utilização de material é quase irrelevante em termos de geração de prémios. Contudo, se um jogador pretender ver o seu nome da lista de pontuação, coloca um número de materiais para bater a pontuação nesse projeto. Alguns jogadores escolhem, inclusivamente, um número especial (por exemplo, 777 ou 1 000) de materiais. Daí resultando que a lista de pontuação mostra, não só o nome, mas também este número especial de materiais. Também existe uma lista de pontuação relativa aos donativos para o departamento. São necessárias doações para desenvolver as capacidades de um departamento. É um conflito latente desenhado para jogadores. Têm de tomar decisões relativamente à atribuição de recursos entre a comunidade do departamento e o seu próprio interesse imediato. A lista de pontuação comunica os resultados da sua decisão (e as ações provavelmente adotadas) aos seus colegas jogadores. Outra (sequência de) ação particular está a completar todas as carreiras oferecidas. Cada uma das profissões concluídas é indicada por uma taça especial na página de estado do jogador. O padrão de transformação das ações em mensagens no registo de atividade de um departamento torna-se óbvio. Aqui a maior parte das ações (Quem é que convidou quem no departamento? Quem é que entrou no departamento? Quem é que fez que donativo? etc.) é automaticamente convertida numa mensagem textual.

O próprio jogo é um meio, proporcionando uma opção de mecânica de jogo e de estética, que pode ser considerada uma mensagem do programador do jogo para 
o jogador. E vice-versa, a aceitação do próprio jogo e de certa mecânica do jogo envia mensagens do jogador para o designer do jogo.

Alguns tipos de media não são fornecidos no Fliplife devido ao género do jogo. $O$ mundo virtual do Fliplife é um website $2 \mathrm{D}$. Por isso, não é possível utilizar informações espaciais no Fliplife e a animação dos gráficos também é limitada. Além disso, a comunicação oral não é suportada pelo jogo. Existem apenas alguns componentes de design de áudio: é implementado um pequeno conjunto de simples efeitos sonoros, por exemplo uma mensagem recebida é anunciada através de um sinal sonoro.

Os processos de comunicação podem ser categorizados pela direção do fluxo de informações. Um atributo do meio é a possibilidade de estar restringido à comunicação unidirecional (informações transferidas apenas do emissor para o recetor) ou permitir a comunicação bidirecional (o emissor e o recetor mudam de papel durante a comunicação). Uma grande parte da comunicação no Fliplife é unidirecional: a maioria das informações de estado apresentadas pertence a esta categoria. O slogan num perfil do jogador pertence à categoria de comunicação unidirecional. Um caso especial é apresentado na Figura 4. Aqui as informações são geradas por dois emissores: o jogador adotou a ação que levou a um estado e subsequentemente o designer do jogo categorizou os números. Assim, o veredito "Socializador" possui duas fontes.

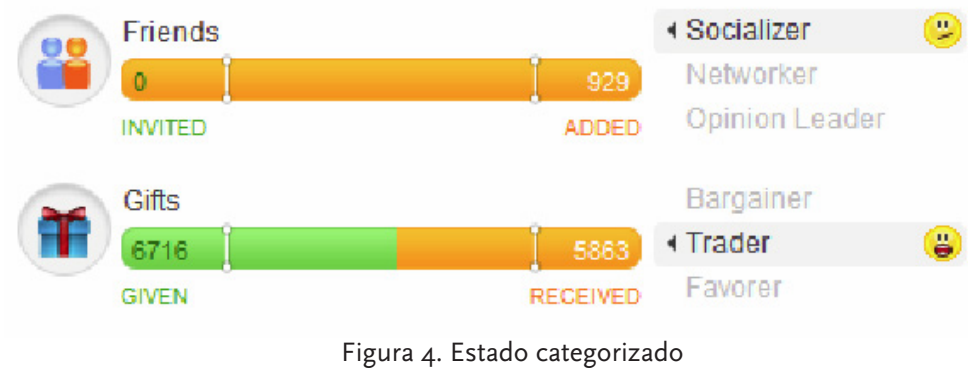

A Amizade no Fliplife (cf. Sec. Um modelo mais realista de Amizade) demonstra a comunicação bidirecional entre dois jogadores. Existe uma variante deste tipo de comunicação designada "Blew-A-Kiss". Esta ação coloca uma marca de beijo no avatar do recetor. É publicamente visível e o recetor pode removê-lo, se não o pretender. Portanto, já é bidirecional nesta fase: nenhuma ação possui sentido. Num cenário posterior, os papéis podem mudar: o jogador "beijado" pode beijar o jogador que beija por seu lado. Uma interação deste tipo possui impacto sobre o nível de amizade dos dois jogadores.

\section{QUEM COMUNICA? ACERCA DE EMISSORES E RECETORES}

O Emissor e o Recetor são componentes importantes do modelo de comunicação. Com base nos exemplos fornecidos, torna-se óbvio que diferentes partes estão envolvidas na comunicação no jogo: os Jogadores constituem um primeiro papel. Estão envolvidos na maioria dos tipos de comunicação de um jogo. Os jogadores nos MOG constituem grupos de jogadores mais pequenos, com o objetivo de seguirem um objetivo partilhado. $\mathrm{Na} \mathrm{Sec}$. Projetos como conflitos desenhados é referido que existem grupos 
altamente coesivos no Fliplife. Muitas vezes utilizam os departamentos como uma unidade organizacional. Isto leva a uma intensa comunicação dentro do grupo. Além disso, um grupo comunica as informações de estado a outros grupos através de listas de classificação. Para além destes exemplos, a coletividade de todos os jogadores pode ser considerada um grupo grande e específico de jogadores.

O designer do jogo criou o jogo e a sua mecânica do jogo, comunicando através do jogo como emissor. Por exemplo, seleciona as informações que são apresentadas na página de perfil ou na lista de classificações. Essas informações podem orientar os jogadores, por exemplo em caso de concorrência. Deste modo, a escolha das informações apresentadas influencia o jogo. Outro exemplo no Fliplife é o Bónus de sessão diária: O jogador recebe um bónus mais elevado por cada dia consecutivo que aceder ao jogo. $O$ jogador, enquanto recetor desta mensagem, pode considerá-la um convite para iniciar a sessão todos os dias. Simultaneamente, o designer do jogo assume o papel de recetor sempre que existir a possibilidade de monitorizar o jogo. Os resultados da monitorização do jogo informam o designer do jogo relativamente à aceitação da mecânica do jogo oferecida. Ao selecionar uma ação, um jogador envia uma mensagem para o designer. Estas informações, provavelmente, podem ser utilizadas para ajustar a mecânica do jogo - como aconteceu no Fliplife quase continuamente.

De qualquer modo, o jogo ocupa o suporte do jogo. Assim, esta função comunica com os jogadores, uma vez que é responsável pela gestão da comunidade e por operar o jogo. Um exemplo relevante é a ação comum do jogador a protestar contra as regras do jogo (cf. Sec. Um modelo mais realista de Amizade). Por sua vez, o suporte do jogo pode reencaminhar esta mensagem enviada por um dos principais grupos de jogadores para o designer do jogo. A ação de eliminar a conta de alguém como exemplo adicional pode ser considerada uma mensagem de um único jogador para o suporte do jogo. Pode, provavelmente, ser um indicador da atratividade do jogo se for executada por grande parte dos jogadores.

A função de um fornecedor de conteúdos necessita de um design de jogo e de software que permita adicionar novos conteúdos ao jogo. No caso do Fliplife, trata-se de um percurso profissional. As empresas podem assumir esta função e comunicar através dos seus percursos profissionais com os jogadores. A atratividade desse conteúdo pode ser medida pelo número de jogadores que o selecionam: uma mensagem enviada do jogador para o fornecedor de conteúdos. Em geral, muitos outros jogos têm conhecimento do fornecedor de conteúdos da função, uma vez que eles podem ser alargados (ou modificados), também, por exemplo através de níveis ou dos designados mods.

\section{O OBJETIVO - POR QUE É QUE AS MENSAGENS SÃO ENVIADAS}

Brüß et al. (2014) inquiriu os jogadores relativamente ao objetivo da comunicação de conversação no Fliplife. A Tabela 2 mostra que existem duas categorias gerais de objetivo de comunicação. 


\begin{tabular}{|c|c|}
\hline Овjetivo & Percentagem \\
\hline Organização dos projetos & $47 \%$ \\
\hline Troca de Material & $60 \%$ \\
\hline Suporte (passivo/ativo) & $45 \%$ \\
\hline Outras preocupações do Fliplife & $28 \%$ \\
\hline Questões Pessoais & $24 \%$ \\
\hline Questões Profissionais & $14 \%$ \\
\hline Atividades nos Tempos Livres & $26 \%$ \\
\hline Outro & $8 \%$ \\
\hline
\end{tabular}

Por um lado, existe uma comunicação relacionada com o jogo para melhorar os resultados do jogo. Um exemplo de orientação para os resultados é a necessidade de coordenação de projetos bónus (cf. Sec. Projetos de bónus como incubadoras de troca): o procedimento tem de ser comunicado a todos os participantes, a hora de início tem de ser determinada em conjunto, os participantes têm de ser recrutados, etc. Outra necessidade propensa para a comunicação decorre de projetos bónus: é necessário recolher material, nomeadamente para melhorar o ganho de um projeto bónus desse género. Conforme descrito no exemplo de troca de material (Sec. Projetos de bónus como incubadoras de troca), trata-se de uma fonte de comunicação que utiliza os media Estado (ao procurar no armazenamento do outro jogador), Texto (para um pedido textual para iniciar negociações) e Ação (quando o material é trocado).

Por outro lado, quase um quarto dos jogadores comunicam sobre questões privadas. $37 \%$ dos participantes declaram que desenvolveram amizades pessoais e quase $10 \%$ conheceram outros jogadores do Fliplife na vida real.

\section{O CODEC: COMO É ENVIADA EXATAMENTE UMA MENSAGEM}

Para condensar uma mensagem, é utilizado um Codificador e um Descodificador. Outra expressão para este fenómeno é Gíria (Siitonen, 2007). O emissor utiliza uma abreviatura para encurtar a mensagem e reduzir o esforço para criar a mensagem. Se o recetor souber qual o significado especial da abreviatura, será capaz de descodificar a mensagem. Este processo funciona independentemente dos media, mas são necessários conhecimentos específicos de descodificação. O Descodificador e o Codificador estão sempre juntos (codec) e são específicos dos media. Na Sec. Projetos como conflitos desenhados, é referido um exemplo do meio texto: a opção Recolher automaticamente que se encontra ativada é acompanhada por um comentário "AA" na conversação do projeto. Além disso, existem projetos especiais que são iniciados para guardar Energia e Material. Para impedir outros jogadores de participarem nestes projetos e, por conseguinte, iniciá-los acidentalmente, existe um comentário "Lager" ("Armazenamento", em alemão). Um outro exemplo do meio gráficos são os ícones emotivos. O Fliplife suporta estes ícones através de uma caixa de seleção (ver Figura 5). Esta seleção já inclui uma função de codificação/descodificação: a descrição de cada ícone apresenta a descrição textual. 


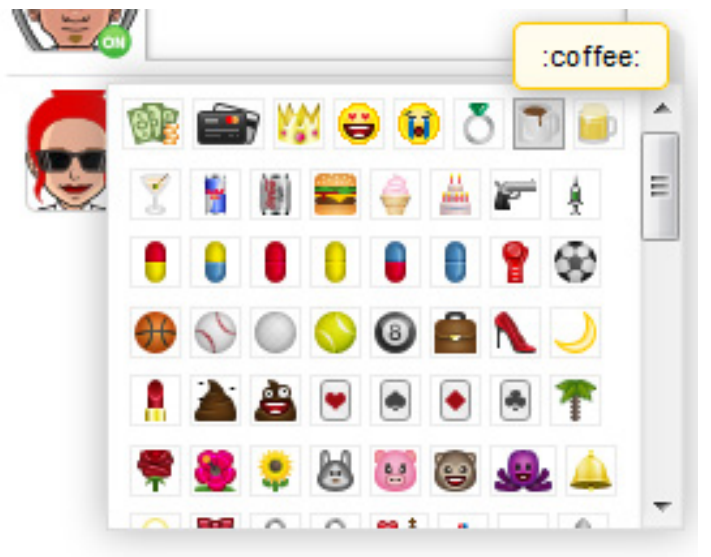

Figura 5. Caixa de seleção das fotografias da conversação

Uma manifestação adicional de transmissão de uma mensagem condensada é uma decoração de avatar específica da profissão. A Figura 6 mostra uma decoração facilmente reconhecível.

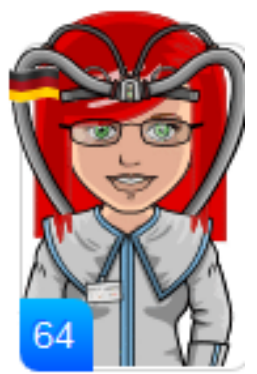

Figura 6. Avatar: percurso profissional "E-Plus"

Um Projeto de bónus é, parcialmente, uma expressão da gíria para um conjunto de ações. Se este termo for referido, o recetor pode traduzi-lo nas ações necessárias. Notoriamente, existem alguns dialetos deste termo da gíria: ao longo do tempo, desenvolveram-se diferentes receitas para executar um Projeto bónus. A partir do contexto "local" do Departamento, o conjunto de ações corretas fica claro.

\section{TRABALHO RELACIONADO: CONSTRUIR FUNDAMENTAÇÕES}

Em suma, depois de uma primeira vista de olhos, chegámos à conclusão de que o Fliplife incentiva - apesar da sua simplicidade - uma quase completa gama de particularidades de comunicação, que podem ser observadas nos jogos de vídeo em geral. De modo a provar esta observação, inicialmente criámos uma fundamentação teórica que proporciona um enquadramento das possíveis formas de comunicação no contexto deste trabalho.

A transferência de informações de um emissor para um recetor constitui uma descrição muito abstrata, comum e simples da comunicação do termo. Com base nesta descrição, desenvolveu-se uma série de modelos de comunicação. Um destes modelos bem conhecido é o modelo de comunicação de Lasswell (Fórmula de Lasswell, Lasswell, 
1948). Este modelo é resumido pela questão "Quem diz o quê através de que canal a quem e com que efeito?". Os componentes deste modelo são o Emissor (ou comunicador, "Quem"), a Mensagem ("diz o quê"), o Meio ("através de que canal"), o Recetor ("a quem") e o Efeito ("com que efeito"). Shannon (1948)apresentou o modo Shannon-Weaver, utilizando termos recorrentes: Emissor, Mensagem, Recetor e Meio. A aplicabilidade deste modelo é vista como sendo limitada para processos de comunicação não técnicos, uma vez que cobre a área da comunicação física (Schmidt \& Zurstiege, 2000). Contudo, os termos comuns podem ser valorizados como indicação adicional para os utilizar num contexto de comunicação possivelmente mais alargado.

O modelo de Lasswell foi sujeito a discussões. Assim, Braddock (1958) adicionou o componente Objetivo ao modelo. Este componente parece ser útil para o nosso trabaIho, a análise da comunicação no Fliplife. Para resumir, utilizamos num modelo geral os componentes Emissor, Recetor, Mensagem, Meio e Objetivo (ver Figura 1).

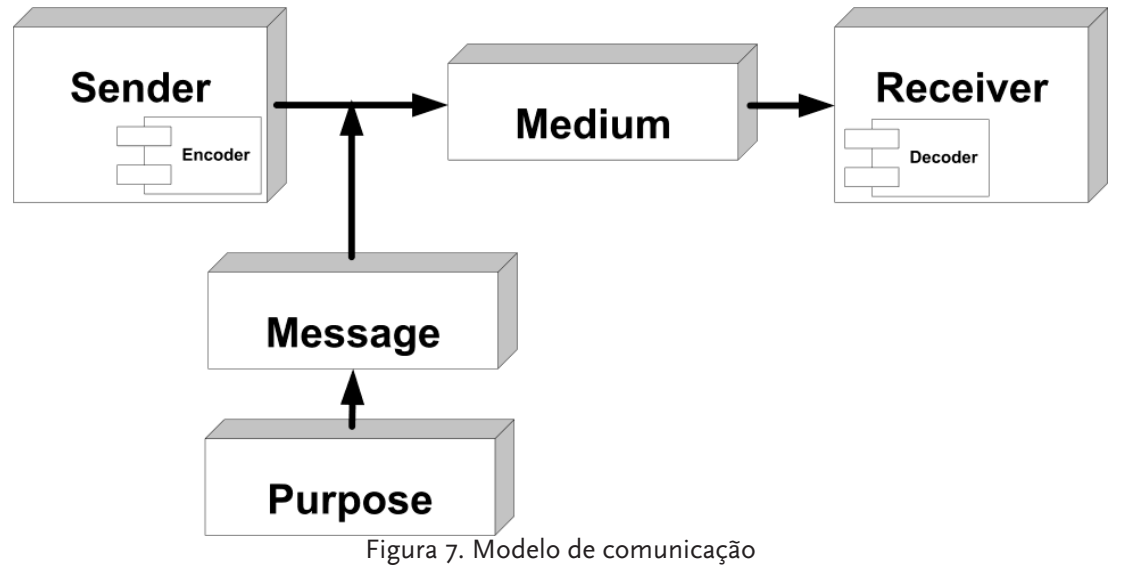

Para além de procurar um modelo de comunicação geral, a sua relação específica com os jogos de vídeo tem de ser esclarecida. Neste contexto, existe uma série de contribuições significativas. Portanto, a comunicação é parte essencial no postulado de Lave \& Wenger, (1991) de aprendizagem situada. Embora, muitas vezes, uma parte consideravelmente elevada da comunicação decorra fora do jogo, a maior parte das vezes também existe um volume de comunicação significativo no jogo, entre jogadores. Outro exemplo decorre da taxonomia de jogadores de Bartle (1996): um dos tipos que ele identificou foi o Socializador. Este tipo de jogador obtém uma grande parte da sua motivação para jogar junto da socialização com outros. Mas também os outros tipos de taxonomia indicam que os jogos estão relacionados com a comunicação em geral. As investigações do tipo Explorador podem ser vistas como uma espécie de comunicação com o programador do jogo. Um jogador do tipo Matador pode utilizar a comunicação verbal e a comunicação não verbal para dominar os seus colegas jogadores. Um Conquistador envia uma mensagem para outros jogadores com as suas estatísticas de jogo, com todas as suas conquistas - se o programador do jogo permitir uma apresentação pública do estado. Além disso, como discutido anteriormente, jogos de vídeo específicos podem funcionar como Terceiros Lugares virtuais. Estes, contudo, estão estreitamente ligados aos tipos 
de comunicação versáteis. Uma observação adicional desses tipos de comunicação seria útil para fornecer uma taxonomia de comunicação em jogos de vídeo. Neste contexto, Siitonen (2007) oferece-nos, no seu trabalho sobre interações sociais em torno do jogo de jogos online de múltiplos jogadores, uma panorâmica dos tipos de comunicação predominantes. A comunicação através do texto é suportada por quase todos os jogos. A comunicação por voz é, frequentemente, possibilitada por software e hardware adicional. A sua utilização depende da cultura específica do jogo. A comunicação não verbal e os avatars são um termo coletivo referente à utilização de outros media para além de texto e de voz no jogo para enviar mensagens em geral. Um exemplo bem conhecido é o design do avatar de alguém. Sugerimos ações completas como outro tipo de comunicação: muitas vezes, as consequências das ações encontram-se publicamente visíveis, por exemplo na página de perfil do jogador (estatísticas do jogador). Siitonen também refere a Gíria na sua enumeração de comunicação. Geralmente, a gíria pode ser definida como "expressões específicas do jogo" que "podem incluir abreviaturas" (Siitonen, 2007, p. 69). Estas expressões contribuem para uma comunicação mais densa. No modelo de Shannon-Weaver, refere-se à função de Transmissor e de Recetor que codificam e descodificam a mensagem (na Figura 7, acrescentamos os componentes Codificador e Descodificador). Em geral, pode constatar-se a utilização de gíria, independentemente do meio.

Outro tipo de comunicação ocorre entre o jogador e o designer do jogo através do jogo (Jordan, 2011). O design de um jogo oferece opções. A forma como um jogador utiliza ou não essas opções pode ser vista como sendo uma mensagem do jogador para o designer do jogo. O facto de os jogadores nunca executarem uma determinada tarefa fornece ao designer uma dica para estudar as razões inerentes a esse comportamento. Esta observação leva a uma definição mais alargada da comunicação como resultado percetível das ações e das não ações. Esta definição inclui Emissor, Recetor, Meio, Mensagem e Objetivo, mas não tira ilações relativamente a estes componentes, permitindo descrever formas de comunicação adicionais.

Existem outros aspetos da comunicação induzida pelos jogos de vídeo. Em primeiro lugar, conforme defendido, acrescentam novas formas de comunicação. Mas, ao mesmo tempo, também perdem alguns tipos de comunicação. Em parte, a falta de comunicação não verbal pode ser atenuada pelo design expressivo dos personagens, um resultado da evolução técnica e da investigação (Tanenbaum, El-Nasr, \& Nixon, 2014).

Outra característica da comunicação nos jogos de vídeo é o número crescente de partes envolvidas. Enquanto uma comunicação verbal inclui, normalmente, duas pessoas, nos jogos de vídeo comunica um espetro mais alargado de funções. Basicamente, poderá encontrar-se a comunicação jogador a jogador. Contudo, existem outros atores, como o Designer do Jogo, o Suporte do Jogo e os Fornecedores de Conteúdos. Todas estas partes comunicam entre si, o que conduz a uma comunicação multifacetada. Claro que alguns destes percursos de comunicação podem ser considerados mais relevantes: a comunicação entre jogadores e o design do jogo como comunicador é inspiradora para a investigação na área dos jogos e para o design de jogos. 


\section{RESUMO}

O Fliplife é um SNG. Contudo, foi desenhado com um enfoque no jogo colaborativo. Esta é uma abordagem diferente daquela que é seguida por outros SNG, direcionadas meramente para a recolha e ornamentação enquanto aspetos motivacionais. Devido à ausência dessa mecânica do jogo e ao seu revestimento purista, o Fliplife negligencia este apelo. Pelo contrário, a sua mecânica de jogo simples incentiva a colaboração e a comunicação entre jogadores. A comunicação origina, quer a necessidade de colaboração orientada para o êxito, quer o interesse dos jogadores nos seus colegas jogadores ou na própria comunicação. Na nossa perspetiva, estes aspetos identificam o Fliplife como um objeto de estudo adequado sobre a comunicação nos jogos de vídeo.

Observámos um grande conjunto de exemplos de comunicação. Estes resultados incluem o facto de o Fliplife poder ser visto como um exemplo de sucesso da comunicação jogador a jogador, o que é realçado pela sua função, também, como Terceiro Lugar virtual. A comunicação no Fliplife é estimulada fora do seu âmbito como advergame. Contudo, conduz a grupos coesivos e, por conseguinte, retém os jogadores no jogo, o que permite às empresas como fornecedores de conteúdos (e, por conseguinte, desempenhando o papel de emissores) alcançar o seu público. Em geral, a mecânica do jogo cria conflitos e, assim, a necessidade de comunicação para solucionar estes conflitos. Neste contexto, o Fliplife pode ser descrito como uma aplicação de sucesso do design do jogo que tem como objetivo fornecer um enquadramento para ser cumprido pelos jogadores. Salen \& Zimmerman (2003: 168) explicam que

"O objetivo de um design de jogo de sucesso é um jogo com sentido, mas o jogo é algo que emerge do funcionamento das regras. Como designer de jogo, nunca é possível desenhar a atividade de jogo diretamente. Só é possível desenhar as regras que estão na sua base. Os designers de jogos criam experiência, mas apenas indiretamente."

Para além da comunicação jogador a jogador, podemos identificar tipos de comunicação adicionais que envolvem o designer do jogo, o suporte ao jogo e os grupos de jogadores. Os jogos de vídeo rejeitam certos tipos de comunicação, mas também permitem novos tipos de comunicação. Valorizamos as ações (ou as não ações) como um tipo de meio para comunicação não verbal (ou não textual).

A principal contribuição deste artigo reside em documentar e categorizar o elevado volume de comunicação que decorre inclusivamente num simples MOG. A comunicação nos jogos não constitui uma questão de esforço tecnológico para criar mundos virtuais (quase realistas), mas uma questão de design de jogos. Por conseguinte, consideramos o nosso trabalho, num segundo passo, como um contributo para proporcionar aos jogos, quer a necessidade de comunicação, quer oportunidades para comunicar.

Utilizámos, no nosso contexto, um modelo de comunicação adequado. Contudo, não se constitui, ainda, como modelo abrangente de comunicação nos jogos de vídeo. As nossas conclusões estarão, certamente, circunscritas pela seleção do jogo. Além disso, foi influenciado pelo nosso ponto de vista específico, que se encontra mais 
estreitamente ligado ao campo dos jogos de vídeo, do que ao grande campo da comunicação. Por conseguinte, futuramente poderemos desenvolver este trabalho, incluindo uma perspetiva mais detalhada relativamente à teoria da comunicação em geral.

\section{REFERÊNCIAS}

Bartle, R. A. (1996), "Hearts, Clubs, Diamonds, Spades: Players Who Suit MUDs", Journal of MUD Research, $1(1), 19$.

Bogost, I. (2010), Cow Clicker - The Making of Obsession. Video Game Theory, Criticism, Design, retrieved from http://www.bogost.com/blog/cow_clicker_1.shtml, date accessed 07/18/2014.

Braddock, R. (1958), "An extension of the 'Lasswell Formula'” Journal of Communication, 8, 88-93, doi:10.1111/j.1460-2466.1958.tbo1138.x.

Brüß, F., Brunner, K., Hünemörder, J., Kühn, S., \& Meisgeier, K. (2014), Fliplife als virtueller Third Place, Bauhaus-Universität Weimar.

Crunchbase: Fliplife. retrieved from http://www.crunchbase.com/organization/fliplife, date accessed $10 / 10 / 2014$.

Gee, J. P. (2008), What Video Games Have to Teach Us About Learning and Literacy, New York: Palgrave Macmillan.

Grabmeier, S. (2012), Mit einem Social Game Mitarbeiter gewinnen. Haufe New Media für Personaler, retrieved from http://www.haufe.de/personal/hr-management/mit-einem-social-game-mitarbeitergewinnen_80_126650.html, date accessed 05/05/2014.

Jordan, C. (2011), Closing the Loop: Fostering Communication In Single Player Games, Gamasutra.com, retrieved from http://www.gamasutra.com/view/feature/134646/closing_the_loop_fostering_.php, date accessed 10/06/2014.

Lasswell, H. D. (1948), "The structure and function of communication in society", in L. Bryson (Ed.), The Communication of Ideas, 37-51, New York, London: Institute for Religious and Social Studies.

Lave, J., \& Wenger, E. (1991), Situated Learning: Legitimate Peripheral Participation, New York: Cambridge University Press.

Männl, N. Y. (2012), fliplife - wenn der Protest gegen unsinnige Updates lilafarben ist. Auto Diva E-Motion er-fahren (Blog), retrieved from http://0511web.de/2012/01/16/fliplife-wenn-der-protest-gegen-updateslilafarben-ist/, date accessed 03/15/2015.

Meyer, M. (2011), Per Spiel zum Traumjob? FORUM - Das Wochenmagazin, retrieved from https://web. archive.org/web/20111130094810/http://www.magazin-forum.de/per-spiel-zum-traumjob, date accessed 03/15/2015.

Müller, N. (2012), Erweiterung von Fliplife mit bauphysikalischen Inhalten. Bauhaus-Universität Weimar, retrieved from http://e-pub.uni-weimar.de/opus4/frontdoor/index/index/docld/1676, date accessed $10 / 03 / 2014$.

Müller, N., Hennig, C., Aubel, M., Hesse, T., \& Schneider, S. (2012), FlipLife als Mitarbeiterrekrutierungsquelle, Bauhaus-Universität Weimar, retrieved from http://e-pub.uni-weimar.de/opus4/frontdoor/index/index/ docld/1572, date accessed 10/03/2014. 
Oldenburg, R. (1999), The Great Good Place: Cafes, Coffee Shops, Bookstores, Bars, Hair Salons, and Other Hangouts at the Heart of a Community,.Cambridge, MA: Da Capo Press.

Rohrl, D. (2009), 2008-2009 Casual Games White Paper. Mt. Royal, NJ, retrieved from http://wiki.igda.org/ Casual_Games_SIG\#White_Papers, date accessed 10/20/2014.

Salen, K., \& Zimmerman, E. (2003), Rules of play: game design fundamentals, Cambridge, MA: The MIT Press.

Schmidt, S. J., \& Zurstiege, G. (2000), Orientierung Kommunikationswissenschaft: Was sie kann, was sie will. Was sie kann, was sie will, Reinbek bei Hamburg: Rowohlt-Taschenbuch-Verlag.

Shannon, C. E. (1948), "A mathematical theory of communication", The Bell System Technical Journal, 27: 379-423, doi:10.1145/584091.584093.

Siitonen, M. (2007), Social Interaction in Online Multiplayer Communities, Jyväskylä : University of Jyväskylä.

Söbke, H. (2014), "FarmVille. Testing limits. Four years. Level 1446" in A. Ochsner, J. Dietmeier, C. C. Williams, \& C. Steinkuehler (eds.), Proceedings Gls 10 Games + Learning + Society Conference (, Pittsburgh, PA: ETC Press, pp. 315-322). ISSN 2164-666X.

Söbke, H., Bröker, T., \& Kornadt, O. (2012), “Social Gaming - Just Click and Reward?” in P. Felicia (ed.), Proceedings of the 6th European Conference on Games Based Learning, Reading: Academic Publishing Limited, (pp. 478-486).

Söbke, H., Hadlich, C., Müller, N., Hesse, T., Hennig, C., Schneider, S., Kornadt, O. (2012), "Social Game Fliplife: Digging for talent - an analysis", in P. Felicia (Ed.), Proceedings of the Gth European Conference on Games Based Learning, Reading: Academic Publishing Limited, (pp. 487-494).

Söbke, H., \& Londong, J. (2015), "A Social Network Game as virtual Third Place: Community Enabler in Virtual Learning Environments?" in Proceedings of EdMedia, Montreal 22.6. -25.6. (to appear).

Soukup, C. (2006), "Computer-mediated communication as a virtual third place: building Oldenburg's great good places on the world wide web", New Media Q Society, 8(3): 421-440. doi:10.1177/1461444806061953.

Steinkuehler, C. A. (2006), "Why game (culture) studies now?", Games and Culture, 1(1): 97.

Steinkuehler, C. A., \& Williams, D. (2006), “Where everybody knows your (screen) name: online games as 'Third Places'”, Journal of Computer-Mediated Communication, 11(4): 885-909. doi:10.1111/j.1083-6101.2006.00300.x.

Tanenbaum, J., El-Nasr, M. S., \& Nixon, M. (eds.) (2014) Nonverbal Communication in Virtual Worlds Understanding and Designing Expressive Characters, Pittsburgh: ETC Press.

Terlutter, R., \& Capella, M. (2013), "The gamification of advertising: Analysis and research directions of ingame advertising, advergames, and advertising in social network games", Journal of Advertising, 42(2-3): 95-112, doi:10.1080/00913367.2013.774610.

Wallace, M., \& Robbins, B. (2006), 2006 Casual Games White Paper, IGDA. retrieved from archives.igda.org/ casual/IGDA_CasualGames_Whitepaper_2006.pdf, date accessed 10/20/2014.

Yee, N. (2014), The Proteus Paradox: How Online Games and Virtual Worlds Change Us—And How They Don't, New Haven: Yale University Press. 


\section{LUDOGRAFIA}

Fliplife GmbH (2010), Fliplife, transferido de http://www.fliplife.com, data de acesso 24/08/2014.

\section{Agradecimentos E financiamento}

Partes das atividades descritas neste artigo foram apoiadas pelo Ministério da Educação e da Investigação Federal da Alemanha (BMBF), com as referências de bolsa n. ${ }^{\circ}$ FKZ 03 IP704 e FKZ 033 Wo11E. Os autores agradecem este apoio e assumem total responsabilidade pelo conteúdo desta publicação. Os autores agradecem, ainda, aos revisores anónimos os seus preciosos comentários.

\section{NOTAS BIOGRÁFICAS}

Heinrich Söbke é investigador de pós-doutoramento no Bauhaus-Institute for Infrastructure Solutions (b.is) Weimar, Alemanha, trabalhando no campo da aprendizagem baseada em jogos digitais na educação em engenharia. Os jogos nas redes sociais constituem uma das áreas centrais do seu trabalho. Foi académico visitante no Department of Curriculum \& Instruction da University of Wisconsin - Madison e do Morgridge Institute for Research, em 2010. Conduz, atualmente, investigação sobre jogos de vídeo como ferramentas de simulação em planeamento de infraestruturas. Antes de entrar para a Bauhaus-University Weimar, em 2009, trabalhou durante 15 anos em projetos industriais como analista de sistemas e como cientista de computadores. Heinrich possui Licenciatura em Engenharia Industrial e Mestrado em Ciências da Informação. Em 2014, defendeu a sua tese de doutoramento sobre uma plataforma de jogo educativa extensiva.

E-mail: heinrich.soebke@uni-weimar.de

Bauhaus-Universität Weimar, Bauhaus-Institute for Infrastructure Solutions (b.is) Coudraystr. 7, 99423 Weimar, Alemanha

Thomas Bröker é coordenador de comunicação de projetos de um projeto de desenvolvimento de seis cursos de aprendizagem mista e de estabelecimento de uma escola profissional na Bauhaus-Universität Weimar. Enquanto doutorando da Faculdade de Engenharia Civil, investiga a adaptação de princípios de design e ensino MMOG como forma de induzir problemas complexos de cenários de aprendizagem situada em educação em engenharia. Como investigador associado de Física da Construção, lecionou durante vários anos sobre a combinação de e-learning e ensino presencial. Foi membro da equipa de desenvolvimento do programa de formação contínua eLearning Bauphysik, responsável por cursos de edifícios com eficiência energética, marketing e design corporativo. Posteriormente, coordenou um grupo de investigação sobre ensino baseado em jogos em ensino de engenharia, desenvolvendo princípios de design e base técnica para ambientes de múltiplos jogadores, uma simulação modular central para cenários de jogo em física de construção e algoritmos para cálculos eficientes em tempo real de equações físicas. 
E-mail: thomas.broeker@uni-weimar.de

Bauhaus-Universität Weimar, Center for Institutional Development Amalienstr.13, 99423 Weimar, Alemanha

* Submetido: 30-11-2014

* Aceite: 15-3-2015 